\title{
Assessing of funegreek (Trigonella foenum-graecum) seeds pharmacological effects against glucotoxicity and lipotoxicity in streptozotocine-induced diabetic rats
}

\author{
Berroukche $A^{1 *}$, Terras $\mathrm{M}^{1}$, Kharoubi $\mathrm{A}^{1}$, Boudia $\mathrm{H}^{1}$, Kharoubi $\mathrm{O}^{2}$, Dellaoui $\mathrm{H}^{1}$, Lansari $\mathrm{W}^{1}$ and $\mathrm{Zerarki}^{1}$ \\ ${ }^{1}$ Research Laboratory of Water Resources and Environment, Biology Department, Faculty of Science, Tahar-Moulay University of Saida, Saida 20000, Algeria \\ ${ }^{2}$ Research Laboratory of Biotoxicology, Biodegradation and phytoremediation, Biology department, Oran University, Oran 31000, Algeria
}

\begin{abstract}
Diabetes mellitus is a common disease, treated either with insulin or oral antidiabetics which have undesirable effects because of their chemical composition. As an alternative, diabetes should be treated by medicinal plants. This study aimed to assess the effects of fenugreek (Fng) seeds aqueous extract on biochemical parameters in streptozotocine-induced diabetic rats. A population of forty rats was divided into 4 groups; normal control, diabetic rats by STZ, diabetic treated with Fng at the dose $1 \mathrm{~mL}(0.5 \mathrm{~g} / \mathrm{kg})$ and non-diabetic treated (ND-Fng). During 30 days of experiments, body weight and biochemical parameters were measured and statistically analyzed using SigmaPlot software. No significant difference in body weight was observed in diabetics animal (DC) (168 $\pm 8.5 \mathrm{~g} / \mathrm{L})$ and diabetic treated with Fng $(167$ $\pm 4.6 \mathrm{~g} / \mathrm{L})$. Significant decrease in blood glucose $(1.16 \pm 0.1 \mathrm{~g} / \mathrm{L})$, triglycerides $(0.64 \pm 0.2 \mathrm{~g} / \mathrm{L})$, serum urea $(0.38 \pm 0.1 \mathrm{~g} / \mathrm{L})$ and creatinine $(8.02 \pm 2.8 \mathrm{mg} / \mathrm{L})$ levels were reported in diabetics treated with TFG compared to diabetic animals non-treated. Fenugreek, or Trigonella foenum-graecum, was able to regulate and maintain glycaemia and lipid profile at normal levels at diabetic animals.
\end{abstract}

\section{Introduction}

Type 2 Diabetes is non-insulin dependent diabetes mellitus (NIDDM) characterized by a chronic hyperglycemia and deficiency in insulin production by $\beta$-cells or insulin cellular resistance [1]. According to International Diabetes Federation (IDF), the diabetic population has been about 415 million, in 2015, and could reaching 642 million diabetics, in 2040 [2]. According to the World Health Organization (WHO), Algerian diabetics was nearly 3 million diabetics and T2D prevalence approached $16 \%$, in 2003 [3]. T2D results from interaction of multiple factors such as sedentary lifestyle, energy-rich diet intake, obesity, hereditary factors and aging [4]. The diabetes complications are the result of the glucotoxicity, lipotoxicity and inflammation, which leads to insulin resistance and islet $\beta$-cell failure. Hyperglycemia promotes protein glycation, structural and functional alteration of proteins which circulating in blood large amounts (Figure 1). Complication of long-term diabetes induces nephropathy, retinopathy, neuropathy and cardiovascular [5]. Increased free fatty acids interacts with $N F \kappa \beta$ signaling pathway that generates reactive oxygen species (ROS) [6,7]. These free radicals activated C Jun $\mathrm{N}$-terminal kinase (JNK) via NFk $\beta$ pathway. JNK inhibited insulin receptor substrate-1 (IRS-1) and blocked glucose transporter type 4 (GLUT 4) [8]. The components of the immune system made changes in adipose tissue, pancreatic islets, vasculature and circulating leucocytes. This deregulation is associated with an increased cytokines, chemokins blood levels, apoptosis and tissue fibrosis [9]. All this molecular and cell mechanisms explain T2D pathogenesis [7]. Nothing really can match oral antidiabetic drugs, insulin treatment, appropriate diet and physical activity. It is the main approach in the T2D treatment.

In return, synthetic chemical drugs have toxicity disadvantages to human health. Oral antidiabetics have toxic side effects. As alternative,

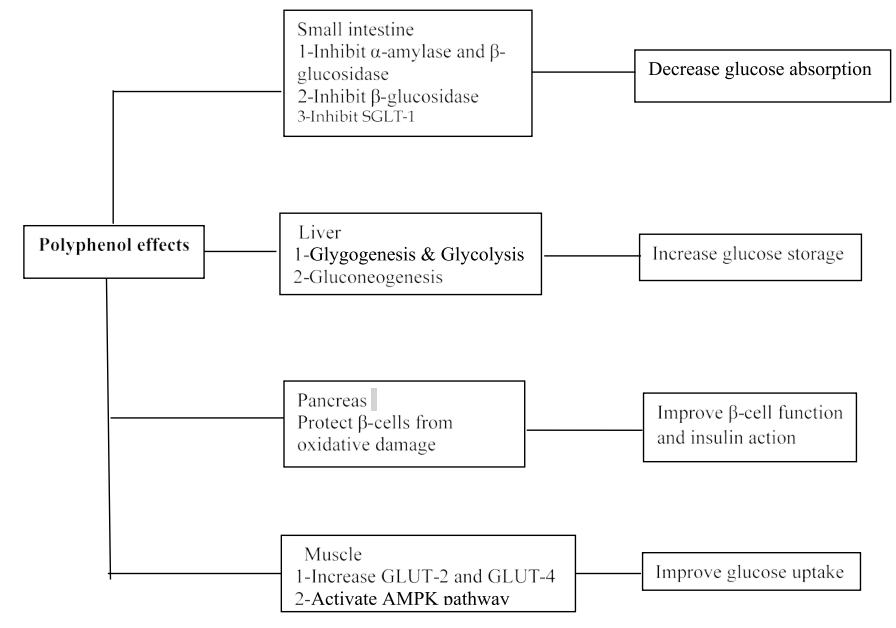

Figure 1. Antioxidant activities of phenolic compounds to enhance glucose homeostasis and insulin resistance

spices and herbs can be used like natural remedies with less toxicity. Medicinal and aromatic plants are the main source of phenolic acids and flavonoids. These bioactive compounds have preventive effects

${ }^{\star}$ Correspondence to: Abdelkrim Berroukche, Biology Department, Faculty of Science, Tahar-Moulay University of Saida, Saida 20000, Algeria, Tel: 00213555972162, 00213798520868, E-mail: kerroum1967@yahoo.fr, berroukche_kerroum@outlook.com

Key words: diabetes mellitus, medicinal plant, Fenugreek, glycaemia, triglycerides

Received: November 06, 2018; Accepted: November 22, 2018; Published: November 28, 2018 
against diabetes. In literature, recent studies suggested the important role of polyphenols influencing glucose metabolism through different process illustrated by the glucose absorption in the intestine, stimulation of insulin secretion from pancreatic b-cells, modulation of glucose release from the liver, activation of insulin receptors, glucose uptake in the insulin-sensitive tissues and modulation of hepatic glucose output [7]. Our research project was focused on Trigonella foenumgraecum (TFG), or fenugreek. This plant belonged to fabaceae family and mostly cultivated in Asian and Mediterranean areas. It is widely used in the folk medicine to prevent diabetes, fever and abdominal colic [7]. TFG has hypocholesterolemic and antidiabetic actions due to the defatted fraction or fiber [10]. The composition of fenugreek seed extract revealed main hypoglycemic and antioxidant compounds such as 4-Hydroxyisoleucine (modified amino-acid), trigonelline (alkaloid), galactomannans (viscouse fiber) and diosgenin (saponin) (Figure 2). The magical molecule of 4-Hydroxyisoleucine has direct effects on the islets of Langerhans and increased releasing insulin to deal hyperglycemia with mainly avoiding the severe hypoglycemia resulting from the therapy of diabetes mellitus $[11,12]$. In addition, fenugreek elevates viscosity in intestines and limits the hydrolysis of carbohydrates slowing the glucose intestinal absorption [11,13]. On another hand, some active ingredients found in fenugreek are involved in hypoglycemic process. Among these compounds, galactomannan (or gelling fiber) and diosgenin which recovering antioxidant enzymatic activities of SOD (superoxide dismutase), GPX (glutathione peroxidase) and catalase in hepatic tissue [10]. Fenugreek allows restoring the kidney function of diabetic rats through its antioxidant activity [14]. This present study aimed to assess the pharmacological properties of fenugreeg seeds against the complications in streptozotocine-induced diabetic rats.

\section{Material and methods}

\section{TFG seed aqueous extract}

Trigonella foenum-graecum, or Fenugreek, seeds were purchased from local market, cleaned, dried and powdered. Amount of $50 \mathrm{~g}$ powdered TFG seeds were dissolved in $500 \mathrm{~mL}$ of boiling distilled water and air-cooled during $30 \mathrm{~min}$. The aqueous extract was filtered, lyophilized and stored. Residue obtained weighted $1.18 \mathrm{~g}$ and the yield of the extraction was $2.36 \%$.

\section{Induction of diabetes rats}

After adaptation of the animals to their environment for 7 days, twenty rats were injected intraperitoneally with prepared STZ (SigmaAldrich Chemical Co., USA) at the dose $60 \mathrm{mg} / \mathrm{kg}$ bw, after overnight fasting. Establishment of diabetes was confirmed by measuring fasting blood glucose in animals after 3 days of STZ injection. Rats, with a glycemia above $150 \mathrm{mg} / \mathrm{dl}$, were considered diabetic.

\section{Animal experiments}

Forty male adult rats were purchased from Pasteur Institute, Algiers, Algeria. Their body weight ranging between 150-250 g. Experimental duration was 30 days. Animals were divided into 4 groups. NC group: normal controls fed with standard diet, DC group: animals were injected with streptozotocine (60 mg / kg), D-Fng group: diabetic animals orally treated with Fng seeds aqueous extract $(500 \mathrm{mg} / \mathrm{kg} /$ day $\sim 1 \mathrm{~mL})$ and ND-Fng group: non-diabetic animals orally treated with Fng seeds in the same experiment conditions (Figure 3).

\section{Body weight measurement}

The body weight of animals was measured every 5 days. This will deduct the body weight gain (\%) according to the following formula:

$$
\frac{f W-i W}{30 \text { days }}(g / \text { days or } \%)
$$

\section{Biochemical study}

Animals were fasted overnight, blood samples drawn from heart under anesthesia. Blood glucose level (g/L) was estimated, every 5 days, by means of On Call Plus glucometer based on glucose oxidase method. Lipid profile (blood triglycerides, total-cholesterol, HDL-C and LDL-C levels) and the kidney parameters (blood urea and creatinine levels) were determined, every 10 days, using an automate-analyzer "MiniVIDAS" (Bio Merieux laboratory, Lyon, France) based on enzymatic method of sandwich type (Figure 3).

\section{Statistical analysis}

Results were represented as mean \pm SEM. Data were statistically analyzed with one-way ANOVA followed by Tukey's multiple comparison test using Sigma-Plot software version 11.0. p-value $<0.05$ was considered statistically significant.

\section{Results}

Variation of body weight and biochemical parameters are showed in Table 1 . Results showed highly significant $(\mathrm{p}=0.001)$ decrease in body weight and body weight gain in diabetic animals $(168 \pm 8.5 \mathrm{~g}$ and $1.7 \pm 0.28 \%$ respectively) compared to controls (203 $\pm 9.5 \mathrm{~g}$ and $2.1 \pm 0.31 \%$ ) (Figure 4). While diabetic animals, treated with fenugreek, did not record significant decrease neither in body weight $(167 \pm 4.6 \mathrm{~g})$ nor in body weight gain $(1.9 \pm 0.11 \%)$. Whereas animals non-diabetic, treated with fenugreek, displayed an increased body weight $(206 \pm 0.53$ g) and also elevated body weight gain $(3.7 \pm 0.7 \%)$.

Blood glucose levels were highly significant in diabetic animals $(1.8 \pm 0.1 \mathrm{~g} / \mathrm{L})$ compared to normal controls $(0.88 \pm 0.0 \mathrm{~g} / \mathrm{L})$ (Table 1) (Figure 4). Fenugreek treatment diminished glycaemia in diabetic animals $(1.16 \pm 0.1 \mathrm{~g} / \mathrm{L})$ and non-diabetics $(0.95 \pm 0.0 \mathrm{~g} / \mathrm{L})$.

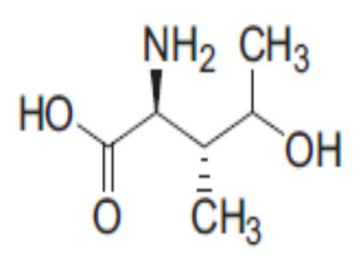

4-Hydroxyisoleucine

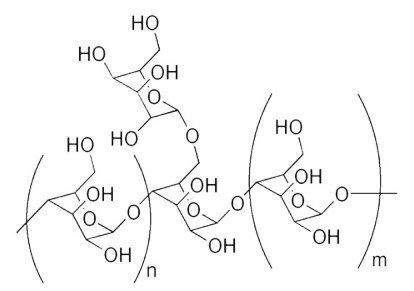

Galactomannans

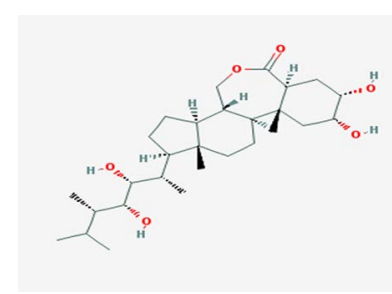

Diosgenin

Figure 2. Structures of hypoglycemic bioactive compounds found in fenugreek seeds [15] 


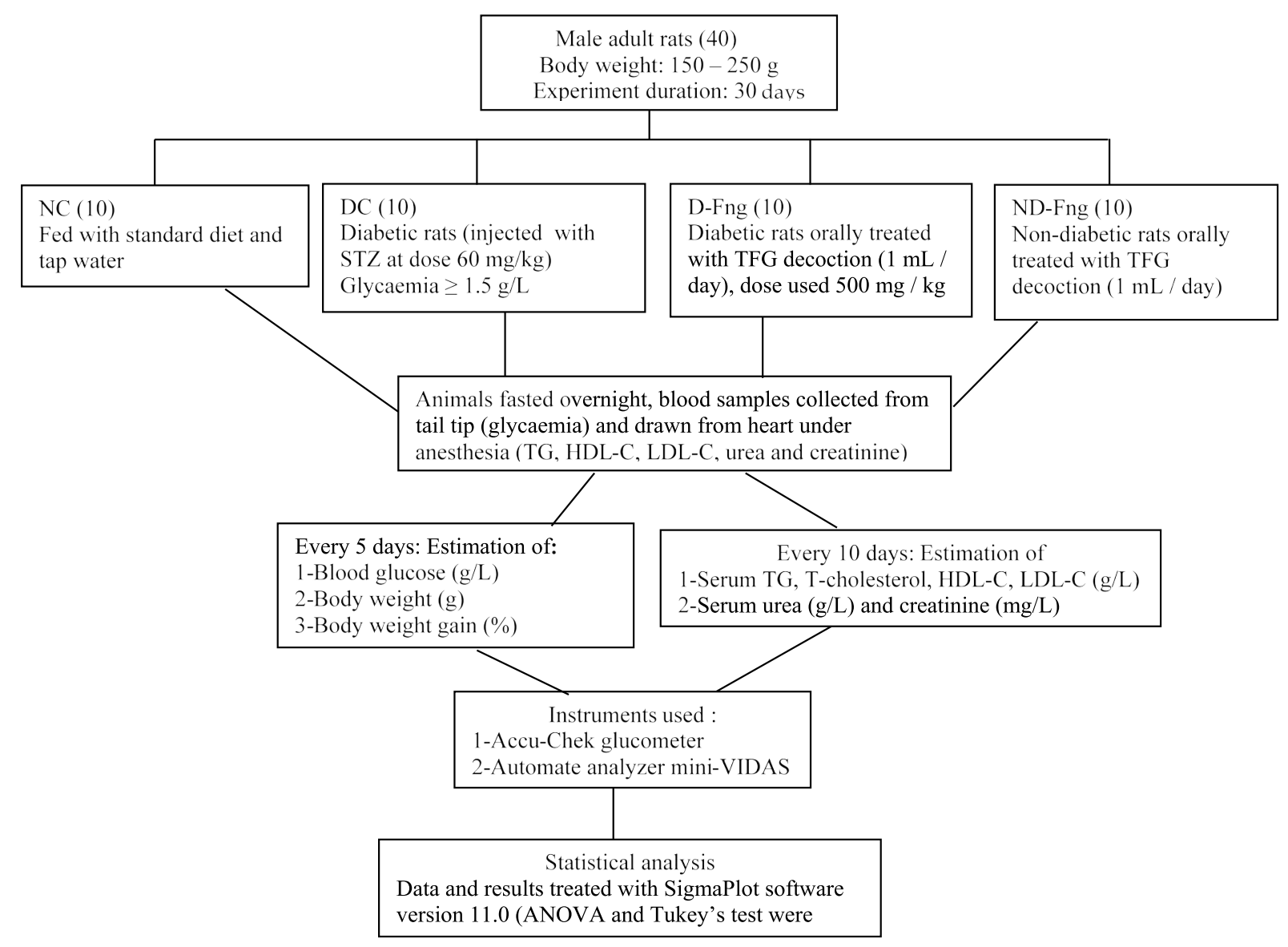

Figure 3. Experimental design of study of hypoglycemic and hypolipidemic TFG seeds decoction in diabetic rats
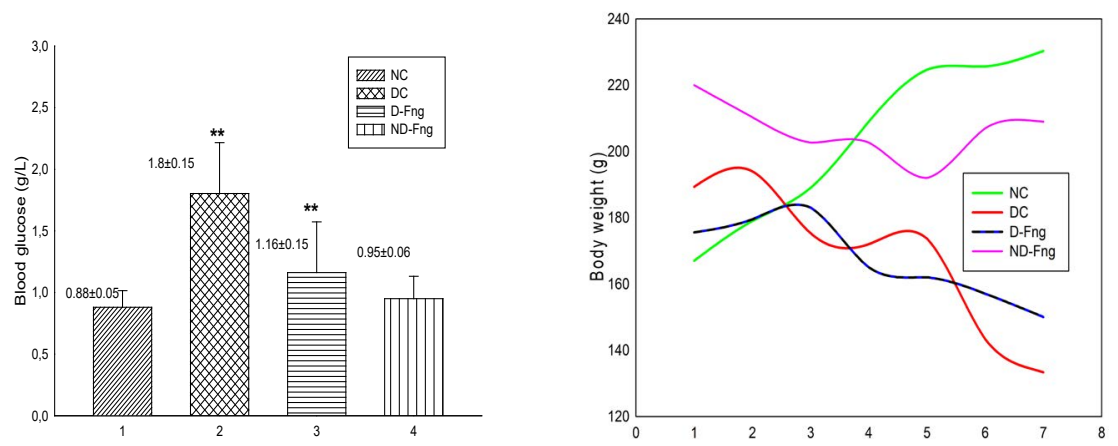

Figure 4. Body weight and blood glucose in diabetic rats treated with fenugreek

Blood triglycerides levels were significantly increased in diabetic animals $(2.51 \pm 0.1 \mathrm{~g} / \mathrm{L})$ compared to controls $(0.55 \pm 0.1 \mathrm{~g} / \mathrm{L})$, D-Fng $(0.64 \pm 0.2 \mathrm{~g} / \mathrm{L})$ and ND-Fng $(0.59 \pm 0.1 \mathrm{~g} / \mathrm{L})(\mathrm{p}<0.001)$ (Table 1) (Figure 5). Furthermore, other biochemical markers such as blood totalcholesterol, HDL-C and LDL-C levels were not significantly different in all groups of animals ( $>$ > 0.05) (Table 1) (Figure 5).

Non-significant difference of results were reported in this present study concerning the blood urea and creatinine levels. Results showed, in diabetic animals, no elevated blood urea and creatinine levels. The treatment of animals with fenugreek did not make significant changes in renal parameters $(\mathrm{p}<0.05)$ (Table 1) (Figure 6).

\section{Discussion}

Funegreek hypoglycemic and hypolipidemiant effect seeds has been confirmed in this study on STZ-induced diabetic rats. Aqueous extract of fenugreek seeds decreased hyperglycemia and serum triglycerides. These results join studies peformed on diabetic model animals [1618]. Previous studies revealed fenugreek composition including main 
Berroukche A (2018) Assessing of funegreek (Trigonella foenum-graecum) seeds pharmacological effects against glucotoxicity and lipotoxicity in streptozotocineinduced diabetic rats

Table 1. Biochemical parameters estimated in diabetic rats treated with fenugreek aqueous extract

\begin{tabular}{|c|c|c|c|c|}
\hline Variables ( \pm SEM) & NC & DC & D-Fng & ND-Fng \\
\hline Body weight (g) & $203 \pm 9.5$ & $168 \pm 8.5^{* *}$ & $167 \pm 4.6$ & $206 \pm 0.53 * *$ \\
\hline Body weight gain (\%) & $2.1 \pm 0.31$ & $1.7 \pm 0.28 * *$ & $1.9 \pm 0.11$ & $3.7 \pm 0.7 * *$ \\
\hline Glycaemia (g/L) & $0.88 \pm 0.0$ & $1.8 \pm 0.1 * *$ & $1.16 \pm 0.1 * *$ & $0.95 \pm 0.0$ \\
\hline Triglycerides $(\mathrm{g} / \mathrm{L})$ & $0.55 \pm 0.1$ & $2.51 \pm 0.1 * *$ & $0.64 \pm 0.2 * *$ & $0.59 \pm 0.1$ \\
\hline Total-cholesterol (g/L) & $1.32 \pm 0.4$ & $1.22 \pm 0.33$ & $1.3 \pm 0.4$ & $1.27 \pm 0.4$ \\
\hline $\operatorname{HDL}(\mathrm{g} / \mathrm{L})$ & $0.41 \pm 0.0$ & $0.56 \pm 0.1$ & $0.35 \pm 0.0$ & $0.41 \pm 0.0$ \\
\hline LDL (g/L) & $0.75 \pm 0.2$ & $1.19 \pm 0.3$ & $0.86 \pm 0.4$ & $0.7 \pm 0.2$ \\
\hline Urea $(\mathrm{g} / \mathrm{L})$ & $0.46 \pm 0.0$ & $0.49 \pm 0.0$ & $0.38 \pm 0.1$ & $0.39 \pm 0.0$ \\
\hline Creatinine (mg /L) & $11.87 \pm 3.7$ & $10.03 \pm 1.8$ & $8.02 \pm 2.8$ & $11.67 \pm 3.8$ \\
\hline
\end{tabular}

NC: normal control, DC: Diabetic Control, D-Fng: Diabetic rats treated with fenugreek, ND-Fng: Non diabtetic rats treated with fenugreek. **: highly signficant difference $(\mathrm{p}<0.01$ )
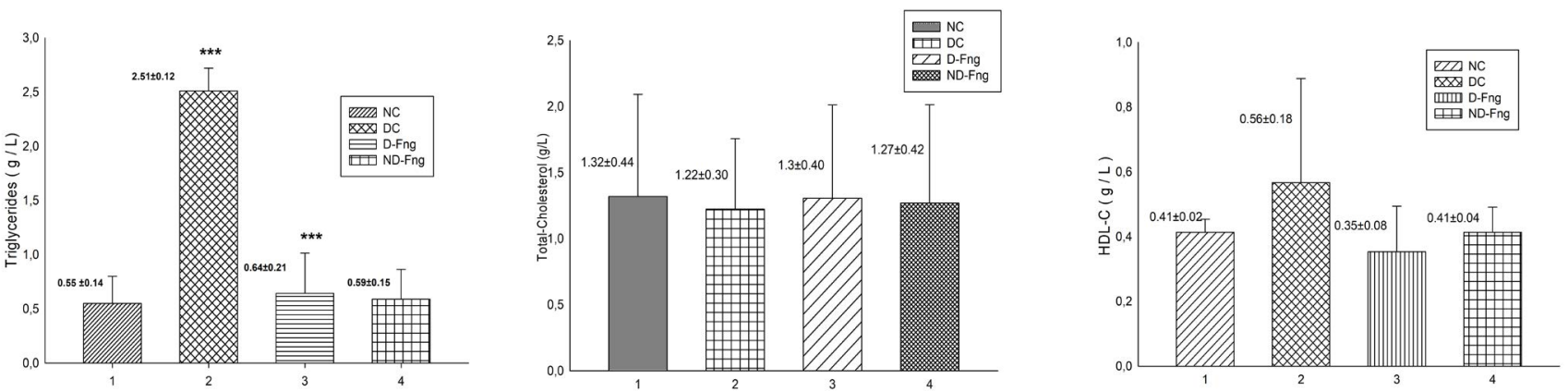

Figure 5. Lipid profile in diabetic rats treated with fenugreek
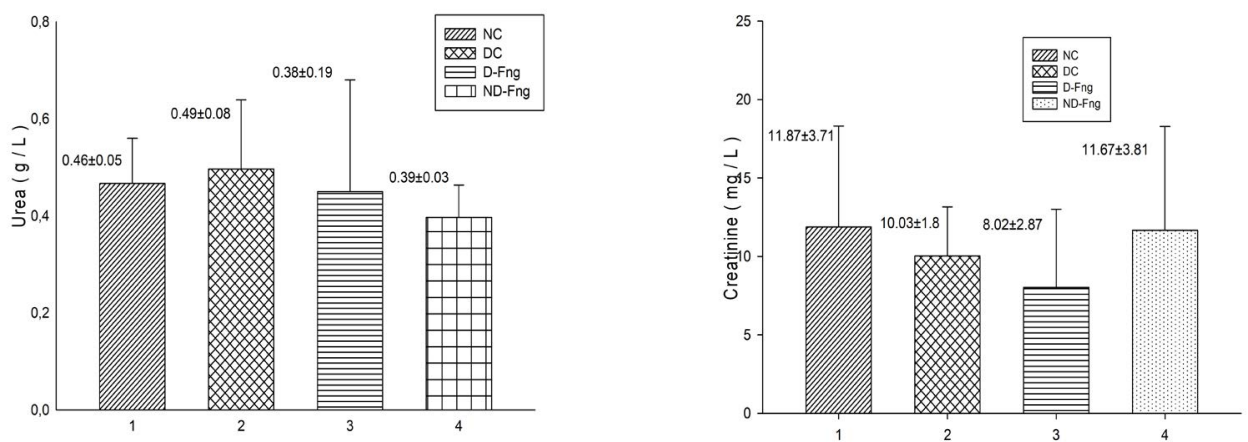

Figure 6. Renal parameters in diabetic rats treated with fenugreek

bioactive compounds [7]. Dietary fiber, or defatted fraction (gum, hemicellulose, cellulose and lignin), is characterized by a high viscosity (52.3\%), dry matter (Ash, lipids and proteins), oligosaccharides (traces $\sim 0.03-1.19 \%$ ), saponins, alkaloids, amino-acids, phenolic acids and flavonoids [12]. Viscouse fibers are known for their hypoglycemic effects through inhibition of digestive enzymes and decreasing glucose intestinal uptake [19]. Diosgenin and Trigonelline specially affected Na-dependant glucose cotransporter-1 (SGLT-1) inducing retardation of glucose absorption, decreased hyperglycemia, resistance insuline and increased glucose tolerance [20]. Magical molecule of 4-hydroxyisoleucine promotes insulin secretion, decreased insuline resistance by activating insulin receptor [10]. Other antioxidant compounds such as vitexin, tricin, naringenin, quercetin and tricin7-O- $\beta$-D-glucopyranoside, belonging to flavonoid family, protect cell system from oxidative stress-mediated cell injury [21]. Our findings are debatable for different reasons; to change the extraction method and to use alcohol as solvent instead of water, to explore the toxicity of Trigonella foenum-graecum, the dose of TFG, Fng seed aqueous extract could be insufficient to promote higher hypoglycemic and hypolipidemic effects as expected and finally to investigate synergy molecular reactions of phenolic compounds elucidating how do this magical molecules acting in cell membrane and decreased glycaemia in diabetic animals and beside also to explore the eventual preventive activities of fenugreek areal plant parts on biochemical parameters.

\section{Conclusion}

Results of this study provide support for a possible use of fenugreek or Trigonella foenum-graecum seeds in managing hyperglycemia and hyperlipidemia preventing the complications associated with type 2 diabetes (diabetes mellitus). Funegreek is considered as an excellent candidate for future studies on diabetes mellitus. Further comprehensive pharmacological investigations, including active crude extract fractionation and bioactive compound studies, should be performed. 


\section{Conflicts of interest}

Authors declare that they have no competing interests.

\section{Acknowledgment}

Authors would like to thank the paramedical team of the biological laboratories of Saida hospital, Algeria.

\section{References}

1. Bastaki S (2005). Diabetes mellitus and its treatment. International Journal of Diabetes and Metabolism 13: 111-134.

2. IDF Diabetes Atlas 2013. Sixth edition.

3. World Health Organization (WHO) 2016. Country profiles for diabetes.

4. Hollander P (2007) Anti-diabetes and anti-obesity medications: Effects on weight in people with diabetes. Diabetes Spectrum 20: 159-165.

5. Forbes JM Cooper ME (2013) Mechanisms of diabetic complications. Physiological Reviews 93: 137-188. [Crossref]

6. Rojas-Olivos A, Solano-Gomez R, Alexander-Aguilera A, Jimenez-Estrada M, ZilliHernandez S, et al (2017) Effect of prosthechea karwinskii (Orchidaceae) on obesity and dyslipidemia in Wistar rats. Alexandria Journal of Medicine 53: 311-315.

7. Bi X, Lim J, Henry CJ (2017) Spices in the management of diabetes mellitus. Food Chem 217: 281-293. [Crossref]

8. Gurrola-Diaz CM, Garcia-Lopez PM, Sanchez-Enriquez S, Troyo-Sanroman R, Andrade Gonzalez I, et al. (2010) Effects of hibiscus sabdariffa extract powder and preventive treatment (diet) on the lipid profiles of patients with metabolic syndrome (MeSy). Phytomed 17: 500-505. [Crossref]

9. Donath MY, Shoelson SE (2011) Type 2 diabetes as an inflammatory disease. Nat Rev Immunol 11: 98-107. [Crossref]

10. Neelakantan N, Narayanan M, de Souza RJ, van Dam RM (2014) Effect of fenugreek (Trigonella foenum-graecum L.) intake on glycemia: a meta-analysis of clinical trials. Nutr J 13: 7. [Crossref]
11. Srichamroen A, Thomson ABR, Field CJ, Basu TK (2009) In vitro intestinal glucose uptake is inhibited by galactomannan from Canadian fenugreek seed (Trigonella foenumgraecum L.) in genetically lean and obese rats. Nutrition Research 29: 49-54. [Crossref]

12. Sharma RD (1986) Effect of fenugreek seeds and leaves on blood glucose and serum insulin responses in human subjects. Nutrition Research 6: 1353-1364.

13. Han HK (2011) The effects of black pepper on the intestinal absorption and hepatic metabolism of drugs. Expert Opinion on Drug Metabolism \& Toxicology 7: 721-729. [Crossref]

14. Pandey H, Awasthi P (2015) Effect of processing techniques on nutritional composition and antioxidant activity of fenugreek (Trigonella foenum-graecum) seed flour. Journal of Food Science and Technology 52: 1054-1060. [Crossref]

15. Smirnov SV, Samsonova NN, Novikova AE, Matrosov NG, Rushkevich NY, et al (2007) A novel strategy for enzymatic synthesis of 4-hydroxyisoleucine: identification of an enzyme possessing HMKP(4-hydroxy-3-methyl-2-keto-pentanoate) aldolase activity. FEMS Microbiol Lett 273: 70-77. [Crossref]

16. Eidi A, Eidi M, Sokhteh M (2007) Effect of fenugreek (Trigonella foenum-graecum L) seeds on serum parameters in normal and streptozotocin-induced diabetic rats. Nutrition Research 27: 728-733.

17. Xue W, Leib J, Li X (2011) Trigonella foenum graecum seed extract protects kidney function and morphology in diabetic rats via its antioxidant activity. Nutrition Research 31: 555-562. [Crossref]

18. Hamza N, Berke B, Cheze C, Le Garrec R, Umar A, et al. (2012) Preventive and curative effect of Trigonella foenum-graecum L. seeds in C57BL/6J models of type 2 diabetes induced by high-fat diet. J Ethnopharmacol 142: 516-522. [Crossref]

19. Venkatesan N, Devaraj SN, Devaraj H (2007) A fibre cocktail of fenugreek, guar gum and wheat bran reduces oxidative modification of LDL induced by an atherogenic diet in rats. Mol Cell Biochem 294: 145-153. [Crossref]

20. Tharaheswari M, Jayachandra Reddy N, Kumar R, Varshney KC, Kannan M (2014) Trigonelline and diosgenin attenuate ER stress, oxidative stress-mediated damage in pancreas and enhance adipose tissue PPAR? activity in type 2 diabetic rats. Mol Cell Biochem 396: 161-174. [Crossref]

21. Gupta SK, Kumar B, Nag TC, Srinivasan BP, Srivastava S, et al. (2014) Effects of Trigonella foenum-graecum (L.) on retinal oxidative stress, and proinflammatory and angiogenic molecular biomarkers in streptozotocin-induced diabetic rats. Mol Cell Biochem 388: 1-9. [Crossref]

Copyright: $\subseteq 2018$ Berroukche A. This is an open-access article distributed under the terms of the Creative Commons Attribution License, which permits unrestricted use, distribution, and reproduction in any medium, provided the original author and source are credited. 